\title{
Ecuador como nodo articulador de la migración senegalesa en América del Sur ${ }^{1}$
}

\author{
Ecuador as the portal of Senegalese \\ migration in South America
}

Andrée Ménard Marleau*

Resumen. El artículo reflexiona sobre las formas y dinámicas de movilidad adoptadas por la migración senegalesa en países de América del Sur, donde se evidencia fundamentalmente el tránsito migratorio. Asimismo, analiza el papel de Ecuador que, por medio de sus políticas migratorias de mayor apertura, se transforma en un nodo principal de conexión en los proyectos migratorios de los senegaleses en esa región del continente. Para ello, se llevó a cabo una investigación de corte cualitativo a través de la aplicación de entrevistas semidirigidas y el estudio de documentos.

Palabras clave. Ecuador, Senegal, tránsito migratorio, nodo migratorio, movilidad.

Abstract. This article looks at the kinds and dynamics of mobility found in Senegalese migration in countries of South America, where transitory migration is typically encountered. It analyzes the role of Ecuador, which - through its open-door migration policies - has become a key entry point linking Senegalese migration projects in the region. To that end, a qualitative research effort was undertaken with the application of semi-guided interviews and document analysis.

Keywords. Ecuador, Senegal, transitory migration, migratory node, mobility.

${ }^{1}$ Este artículo surge de los resultados de investigación de la tesis iIrse o quedarse? Las formas y dinámicas de movilidad de los migrantes senegaleses en América del Sur (2007-2016), elaborada para la obtención del título de maestría en sociología en la Facultad Latinoamericana de Ciencias Sociales (Flacso), Ecuador.

* Maestro en Sociología por la Facultad Latinoamericana de Ciencias Sociales (Flacso), Ecuador. 



\section{Introducción}

La presencia creciente de africanos en América del Sur en las últimas décadas, y en concreto de senegaleses, apunta hacia varias razones articuladas: las desigualdades generadas por el capitalismo global; las restricciones migratorias crecientes en Europa, agravadas por la mediatizada crisis en torno al asilo; y las informaciones sobre bonanza económica que han circulado durante cierto tiempo con respecto a algunos de los nuevos destinos en la región sudamericana (Kabunda, 2007; Wagbou, 2008).

Argentina es el principal lugar de instalación dentro de la región. Su conformación como espacio de atracción de senegaleses, nigerianos, guineanos, marfilenses, malienses o congoleses, entre otras poblaciones africanas (Maffia, 2010; Morales, 2011; Zubrzycki, 2013), se produjo entre la última década del siglo XX y la primera del siglo XXI. Zubrzycki (2013) confirma que en los últimos años los senegaleses han llegado a ser el grupo más numeroso dentro de los migrantes subsaharianos. Como lo reporta Kleidermacher, «los datos de la Dirección Nacional de Migraciones dan cuenta de un subregistro de esta población al ingresar por pasos fronterizos no habilitados, lo que hace difícil estimar su número». No obstante, la Asociación Senegalesa en Argentina calcula que son alrededor de 3 mil senegaleses, mientras que otros miembros de la comunidad afirmaron que eran casi 5 mil (Kleidermacher, 2012). Su llegada a Argentina se debe a una combinación de factores de orden social - los vínculos con la comunidad senegalesa que se ha establecido progresivamente en el territorio-y de orden económico - el trabajo disponible y accesible mediante la conformación de redes.

El arribo a este país no suele producirse de forma directa, antes tienen lugar varias estancias transitorias por otras naciones (Zubrzycki, 2013). Los senegaleses no pueden ingresar a Argentina sin visa, tampoco tienen la posibilidad de solicitarla desde Senegal porque no hay representación diplomática argentina en dicho país. Es por eso que los migrantes desarrollan formas de movilidad específicas para alcanzar el destino deseado y el tránsito es una de las principales estrategias migratorias.

En ese sentido, este artículo pretende evidenciar el papel que desempeña Ecuador como nodo articulador y lugar de tránsito de la migración senegalesa en América del Sur. Junto con Brasil, en los últimos años se ha conformado como un punto de entrada a la región, encadenando trayectos que implican otras 
naciones como Perú y Bolivia. El tránsito migratorio por determinados territorios se convierte en una estrategia de movilidad que permite a los migrantes concretar su proyecto migratorio y mitigar las restricciones impuestas en los lugares de destino.

Es pertinente comentar que más allá de ciertas contribuciones generales sobre migración senegalesa en América Latina o en Argentina, ${ }^{2}$ se trata del primer trabajo en el que se analiza en específico la función que cumple Ecuador como nodo geográfico dentro de la dinámica internacional de la migración senegalesa. Ecuador se emplaza como país de acogida y de tránsito de migrantes extracontinentales, y un punto geográfico importante en la transformación y la complejidad de las dinámicas de movilidad de los senegaleses.

El artículo se organiza en cuatro segmentos: base teórica acerca del tránsito migratorio, metodología, contexto del trabajo de investigación y principales hallazgos. Por un lado, se demuestra cómo el territorio ecuatoriano se ha configurado como nodo articulador entre Senegal y América del Sur, y por el otro, la forma en que el tránsito es la estrategia migratoria central de los senegaleses en su paso hacia Argentina.

\section{El tránsito en tanto práctica y espacio de las migraciones internacionales contemporáneas}

Con la influencia de la globalización en los flujos migratorios internacionales se crea una amplia variedad de movimientos migratorios que contradicen la idea, mantenida durante mucho tiempo, de que las migraciones internacionales corresponden en exclusiva a movimientos de población de países del sur hacia países del norte, de la periferia hacia el centro. Antes se suponía que los países en vías de desarrollo eran estrictamente productores de mano de obra migrante que, en búsqueda de una vida mejor, se desplazaba hacia los industrializados. Esta perspectiva exponía, por lo tanto, una visión occidentalocéntrica del fenómeno

\footnotetext{
${ }^{2}$ De las investigaciones disponibles destacan el trabajo de Kleidermacher (2012), que examina el proceso migratorio de los senegaleses a Argentina, y el de Maffia (2007 y 2010) sobre la migración africana en ese país desde una perspectiva antropológica. En la misma línea se encuentran los estudios de Zubrzycki y Agnelli (2009), Wagbou (2008) y Traoré (2009). Finalmente, existen investigaciones realizadas por la Organización Internacional para las Migraciones (OIM) y el Alto Comisionado de las Naciones Unidas para los Refugiados (ACNUR) que exploran de manera más general el fenómeno creciente de la migración africana a América Latina.
} 
de las migraciones internacionales (Castagnone, 2011) que necesita ser renovada.

Actualmente se observa la existencia de una variación real en los movimientos migratorios contemporáneos que provoca su diversificación (Lacomba, 2002). En efecto, a una mayoría de migrantes potenciales no se le permite pasar las fronteras hacia los países del norte, otros carecen de los medios para irse a un destino tan costoso y lejano, algunos prefieren destinos más factibles. Además, existen flujos importantes al interior de las regiones menos desarrolladas, entre países desarrollados, o entre países desarrollados y en desarrollo. Si bien no se puede negar que la atracción por los países desarrollados sigue presente en el imaginario de los migrantes provenientes de la periferia, es clave reconocer que por diversas circunstancias el destino final de muchos será distinto al planeado en un inicio.

Es precisamente frente al contexto actual, caracterizado por el predominio del capitalismo neoliberal, el debilitamiento del Estado y el progreso de las tecnologías de la comunicación y del transporte, que se ha producido la expansión del tránsito migratorio como una de las formas de movilidad característica de la globalización. Tal término surgió en la década de 1970 (Álvarez, 2011), cuando aumentaron los flujos migratorios sur-norte, hecho que reflejaba la disparidad económica, social y política entre ambos polos (Castles, 1993). En ese contexto, no solamente incrementaron las migraciones de manera general, también lo hicieron las migraciones en tránsito. Sin embargo, hasta la década de 1990 se consolidó este concepto en la teoría sobre las migraciones internacionales para remitirse a la situación intermedia entre la salida del país de origen y la llegada al lugar de destino (Álvarez, 2011; Duvell, 2012).

De modo convencional, el tránsito migratorio se explica como el resultado de una atracción hacia los países ricos, objetivo final del proyecto migratorio (Duvell, 2012). La emergencia del fenómeno se relaciona estrechamente a motivaciones políticas que desean contrarrestar las migraciones no deseadas. Por ende, para muchos el tránsito migratorio posee una connotación negativa similar a la migración irregular (Duvell, 2012). En opinión de Castagnone (2011), el término ha sido pensado además desde una perspectiva eurocéntrica, ya que remite a los flujos migratorios que se dirigen en especial hacia Europa como destino final.

Desde una perspectiva más sociológica, Papadopoulou-Kourkoula (2008) adopta una definición más compleja. Define el tránsito migratorio como la situación 
entre emigración e instalación, que supondría una estadía indefinida del migrante, regular o irregular, y que puede desarrollarse en una migración futura dependiendo de factores estructurales e individuales (Papadopoulou-Kourkoula, 2008 citado en Duvell, 2014). Como lo reporta Duvell (2014), esta definición reconoce que las intenciones migratorias están sujetas a cambios y, por lo tanto, el destino final puede transformarse en punto intermedio, al igual que un punto intermedio puede devenir el destino final. Sólo a posteriori se puede determinar si una estadía en un lugar es temporal o no (Papadopoulou-Kourkoula, 2008 citado en Duvell, 2014).

\section{El tránsito migratorio como forma de movilidad de los migrantes senegaleses en América del Sur}

El concepto de tránsito migratorio ha sido entendido y estudiado desde diferentes ejes: como un espacio (Álvarez, 2015; Icduygu, 2012), como la condición de un sujeto (Cassarino y Fargues, 2006, citado en Marconi, 2008) o como una práctica (Duvell 2012; 2014). Este artículo se centra en la comprensión del tránsito como un espacio y una forma determinada de movilidad. Sobre la primera acepción, Álvarez (2015) explica que las zonas de tránsito son un producto del capitalismo global, ya que satisfacen la demanda de mano de obra barata mientras que, paradójicamente, constituyen sitios de estricto control migratorio. Asimismo, los lugares de tránsito también se caracterizan por ser zonas marcadas por la violencia, la impunidad y las actividades ilegales (Álvarez, 2015).

De modo semejante, Icduygu (2012), concerniente a Europa y sus periferias (Turquía en particular), asevera que la construcción política del tránsito y de sus espacios geográficos está estrechamente vinculada con procesos más globales de securitización de las migraciones internacionales. Tales procesos, cada vez más restrictivos y selectivos, han moldeado los flujos migratorios internacionales contemporáneos con la creación de zonas de tránsito para los migrantes internacionales (Icduygu, 2012). Dentro del nuevo orden migratorio no hay que perder de vista que los países del sur atraen a población migrante y que, en la reproducción de un orden desigual, se sitúan como países de salida y tránsito; es decir, cumplen una función fundamental como nodos articuladores de migraciones más amplias que interconectan diversos países en varios continentes.

Referente al tránsito migratorio como forma de movilidad, se trata de una situación intermedia, en proceso, entre la salida del lugar de origen o lugares 
intermedios y la llegada e instalación en otros. Es una etapa indefinida en la que el migrante puede estar en situación regular o irregular. Además, su desarrollo siempre es determinado por diversos factores estructurales y de carácter individual (Papadopoulou-Kourkoula, 2008, citado en Duvell, 2014). El desarrollo constituye una estrategia ante las políticas de control y de securitización que caracterizan el régimen internacional de las migraciones, pues posibilita el proceso migratorio gracias a las redes y las comunidades transnacionales que acompañan o complementan esa forma de movilidad. En definitiva, el tránsito migratorio adquiere su significado actual debido al contexto estructural en el cual tiene lugar - la globalización - y se construye y alimenta de la existencia de redes transnacionales que son originadas por las dinámicas propias de la globalización.

El tránsito migratorio se desarrolla en función de distintos factores como la presencia de fronteras porosas, de controles y políticas migratorias más o menos abiertos dependiendo de coyunturas políticas y económicas. La posición geográfica estratégica de un país dentro de un sistema migratorio también se considera un factor explicativo (Duvell, 2012). Sobre todo, el tránsito se origina por la dificultad de ingresar legalmente a la mayoría de los países, lo cual obliga a los migrantes a emprender viajes complejos y peligrosos. Según esta visión el tránsito migratorio sería, en definitiva, una respuesta de la población migrante a los regímenes cambiantes de control migratorio.

\section{La metodología: el estudio de caso}

Se empleó una metodología cualitativa en la que se combinaron el análisis estadístico, la entrevista semidirigida y no dirigida y la observación. El método elegido fue el estudio de caso, en el que se considera la migración de senegaleses a Ecuador como un proceso social localizado en un contexto, espacio y tiempo determinados. En ese sentido, el caso se delimita por una unidad social específica (los migrantes senegaleses) y por el espacio geográfico conformado por tres polos (Senegal como punto de partida, Ecuador como lugar de tránsito y Argentina o Brasil como lugares de destino) así como por una temporalidad concreta $(2007-2017){ }^{3}$

${ }^{3}$ La temporalidad escogida corresponde al cambio en las políticas migratorias de Ecuador y que altera el perfil de las migraciones en ese país. 
Concerniente a las técnicas de recopilación de información se recurrió, en un primer momento, al análisis de estadísticas reportadas por la administración pública ecuatoriana. A través del acceso a censos y estadísticas nacionales y provinciales disponibles (INEC, 2007-2016), ${ }^{4}$ se examinó la información sobre los flujos migratorios oficiales de los senegaleses en Ecuador durante el periodo 2007-2017, los cuales se vinculan con los cambios en la política migratoria ecuatoriana.

Con el propósito de apoyar y confirmar los datos estadísticos se aplicaron 30 entrevistas semidirigidas y no dirigidas en cuatro grupos de actores: migrantes, académicos, funcionarios y miembros de ONG. En cuanto a los migrantes, se establecieron entrevistas con tres miembros de la comunidad senegalesa presente en Argentina, a un senegalés radicado en Canadá y a seis africanos que viven en Ecuador provenientes de Nigeria, Camerún, Ghana, Benín y Argelia. Las entrevistas evidenciaron las formas de movilidad, los recursos y las rutas que facilitan los desplazamientos, así como los elementos comunes que se desprenden de sus experiencias migratorias, la configuración de la migración de tránsito y el uso de redes.

Otras entrevistas fueron realizadas a expertos del fenómeno: tres personas del Consejo Nacional de Investigaciones Científicas y Técnicas (Conicet), cinco funcionarios del Ministerio de Relaciones Exteriores y de Movilidad Humana (MREMH), del Gobierno Autónomo Descentralizado de Pichincha (GAD-Pichincha), de la Defensoría Pública de Ecuador y de la Comisión Nacional para los Refugiados de Argentina (Conare). También se consideró importante conversar con organismos internacionales y ONG que atienden, entre otras, a población africana en búsqueda de asistencia humanitaria y asesoría legal. En ese caso se entrevistaron a tres personas del Alto Comisionado de las Naciones Unidas para los Refugiados (ACNUR) en Ecuador, una de Asylum Access Ecuador, y una más del Comité Permanente por la Defensa de los Derechos Humanos.

Finalmente, se llevaron a cabo encuentros con personas que tenían relación con población senegalesa: un profesor de cursos de español en La Plata, Argentina; un estudiante colombiano cercano a la comunidad africana radicada en Quito, Ecuador; tres profesionales del cine argentino que participaron en la realización del documental Magni fi: estoy aquí acerca de la migración senegalesa en su país; una estudiante de posgrado que investiga el tema senegalés en Buenos Aires; y

${ }^{4}$ Base de datos de la Unidad de Gestión de Movilidad Humana del Gobierno Autónomo Descentralizado de Pichincha (GAD-Pichincha), 2014-2015. 
un profesional que trabaja en las comunidades con migrantes senegaleses en la capital argentina. De igual manera, se aplicó la técnica de la observación en espacios específicos de reunión y socialización de la población africana en Quito, ello brindó información de sus redes migratorias, los lugares donde viven o trabajan. Dichos espacios se sitúan en los barrios La Mariscal, La Tola e Iñaquito, aparte de algunos restaurantes e iglesias africanos de la capital ecuatoriana.

\section{El contexto ecuatoriano de «libre circulación»}

Históricamente, Ecuador ha sido un país emisor de migrantes. Sin embargo, esa situación se ha modificado y vuelto más compleja desde principios de los años 2000. Como advierte Álvarez, «Ecuador actualmente ha adoptado una quíntuple condición migratoria: ser al mismo tiempo un país emisor, de destino, de tránsito, de retorno (forzado o voluntario), y de migración interna» (2012:3). En los últimos años Ecuador se ha ubicado, a escala global, en un punto estratégico dentro de las rutas clandestinas que los migrantes recorren con el fin de llegar a Estados Unidos (u otras naciones). Así, opera una compleja industria migratoria en y desde Ecuador que habilita el cruce de diversas fronteras nacionales (Álvarez, 2012).

Entre las razones por las cuales la condición migratoria ha cambiado de modo drástico en los últimos años se encuentra la implementación de una política de "fronteras abiertas» efectiva a partir de 2008. En ese entonces, el marco aperturista de la Constitución de Montecristi y la idea de ciudadanía universal ${ }^{5}$ impresa en la misma, propició la apertura de las fronteras del país a todos los ciudadanos del mundo y permitió el ingreso sin necesidad de visa por un periodo de 90 días al año.

A consecuencia de la entrada en vigor de esta política el ingreso de extranjeros al país (que no implica su instalación temporal o permanente) incrementó de manera significativa y progresiva en los últimos años. Según datos oficiales del Instituto Nacional de Estadística y Censos (INEC), en 2014 se registraron 1 millón 556 mil 991 ingresos, que contrastan con los 937 mil 487 reportados en

${ }^{5}$ Según el artículo 416 de la Constitución de la República del Ecuador de 2008, el principio de ciudadanía universal se define como «la libre movilidad de todos los habitantes del planeta y el progresivo fin de la condición de extranjero como elemento transformador de las relaciones desiguales entre los países, especialmente Norte-Sur» (Asamblea Constituyente, 2008). 
2007 (INEC, 2014). Colombianos, peruanos, estadounidenses, venezolanos, panameños y españoles conforman las poblaciones con mayor presencia (INEC, 2014). Lo anterior indica que la migración es intrarregional y de países del norte, esta última se asocia a población jubilada o a profesionales con alta calificación.

En cuanto a la llegada de personas provenientes de países africanos y asiáticos, aunque han aumentado, las cifras son mínimas en comparación con los países mencionados. Los datos del INEC permiten apreciar que en 2014 entraron al país 4 mil 648 personas. Tales cifras muestran que la presencia de población senegalesa es mayor en comparación a otras nacionalidades africanas. ${ }^{6}$

\section{La configuración del territorio ecuatoriano como nodo articulador entre África y América del Sur}

El tránsito por Ecuador: dinámicas y datos

La investigación confirmó el papel desempeñado por Ecuador como lugar de tránsito hacia Argentina y Brasil, en un contexto y tiempo determinados. Las entrevistas a migrantes africanos establecidos en Quito lo constatan: Ecuador es un punto geográfico estratégico y de conexión global entre continentes. Steve, migrante camerunés ${ }^{7}$ radicado en Quito desde 2004, insistía en que los migrantes africanos no consideran al país como un lugar de instalación, no es una «tierra de oportunidades». Para muchos el objetivo es llegar a Estados Unidos u otros países que son percibidos en esos términos. Una funcionaria del gobierno autónomo de Pichincha ${ }^{8}$ explicaba que se trata con claridad de una migración de tránsito, que puede durar meses o años, pero su intención no es, en ningún caso, quedarse en el país.

${ }^{6}$ Dichas cifras no representan necesariamente la realidad, pues existe un subregistro de las entradas de los africanos que optan por rutas de ingreso clandestinas.

7 Entrevista realizada con Steve, en Quito el 21 de febrero de 2017. Su caso es particular. Algunos africanos entrevistados durante el trabajo de campo migraron a Ecuador hace muchos años y, por lo tanto, sus aspiraciones y trayectorias migratorias son distintas a las de otros que sólo pasaron de forma efímera. En concreto, Steve y su familia tienen un restaurante en el barrio de La Mariscal en Quito, y ha conocido a africanos de Somalia, Sudán, Etiopía, Kenia o Senegal. Cabe resaltar que no toda la migración africana que llega a Ecuador sale del país tan abruptamente como la senegalesa. En contraste con otro caso de migración africana, como la nigeriana (entrevista realizada con Peter en Quito el 8 de febrero de 2017), ellos sí se establecieron y crearon un anclaje en el país.

${ }^{8}$ Entrevista realizada en Quito el 22 de febrero de 2017. 
Quizá, entre las poblaciones africanas, los senegaleses son quienes más consideran a Ecuador como lugar de tránsito. Los datos estadísticos lo demuestran: antes de 2007, fecha en la cual la política de «puertas abiertas» aún no era efectiva, los senegaleses llegaban a Ecuador en cantidades muy restringidas. Las entradas tampoco fueron notables entre 2007 y 2011, con un promedio de 17 y 32 arribos por año (INEC, 2007; 2008; 2009; 2010; 2011) (cuadro 1). A partir de 2012 empiezan a producirse cambios y se incrementa la migración senegalesa; aquellos que no pueden ingresar regularmente a Argentina y que carecen de visa brasileña buscan alternativas. En ese momento se desarrolla una nueva ruta migratoria entre Senegal y Argentina pasando por Ecuador.

De esta forma, en 2012 se registró la entrada de 247 senegaleses (INEC, 2012); un año más tarde, la cifra se elevó a mil 383 ingresos (INEC, 2013). Dicho aumento continuó hasta 3 mil 473 en 2015 (INEC, 2015). En total, de 2007 a 2016, se reportaron 7 mil 111 entradas de senegaleses, de las cuales 6 mil 931 ocurrieron entre 2012 y 2015.

\section{GRÁFICA 1}

Entradas de migrantes senegaleses entre 2007 y 2016

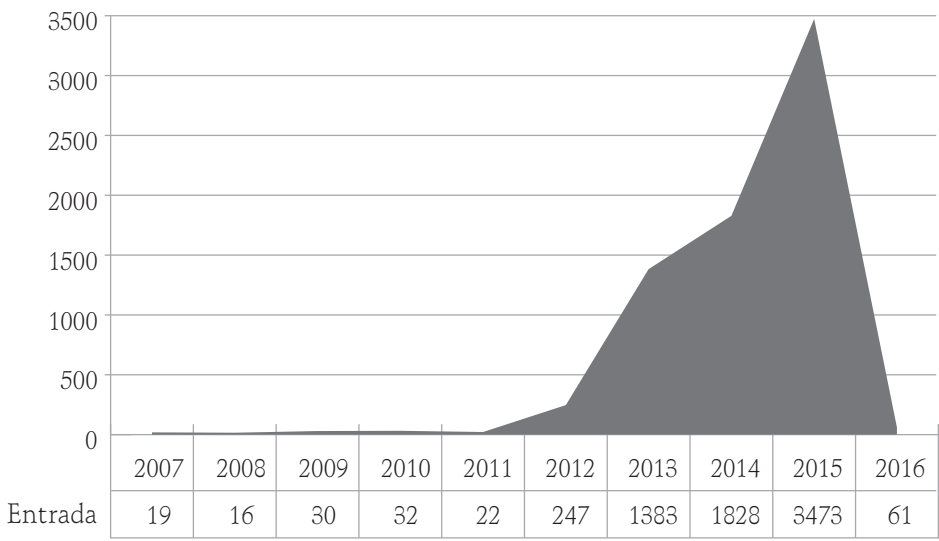

Fuente: elaboración propia con datos del INEC (2007-2016)

Al estudiar con detenimiento lo sucedido entre 2012 y 2015, resaltan ciertas características de los individuos: el grupo de edad mayoritario fue de 25 a 29 años, un grupo que no predominó con anterioridad ni posteriormente a ese lapso (INEC, 2012; 2013; 2014; 2015). Representan entre 34.8 y 39.5 por ciento de la población senegalesa que ingresó al territorio ecuatoriano (INEC, 2012; 2013; 2014; 
2015). Antes y después de este lapso, es decir en 2011 y 2016 respectivamente, el grupo de edad mayoritario era de 50 a 59 años (INEC, 2011; 2016).

\section{CUADRO 1}

Entradas de migrantes senegaleses entre 2007 y 2016 (por edad)

\begin{tabular}{ccccc} 
Año & $\begin{array}{c}\text { Total } \\
\text { senegaleses }\end{array}$ & $\begin{array}{c}\text { Franja etaria } \\
\text { mayoritaria }\end{array}$ & $\begin{array}{c}\text { Total de senegaleses } \\
\text { franja etaria mayor }\end{array}$ & Porcentaje \\
\hline 2016 & 61 & $50-59$ & 20 & 32.78 \\
2015 & 3473 & $25-29$ & 1239 & 35.67 \\
2014 & 1828 & $25-29$ & 690 & 37.74 \\
2013 & 1383 & $25-29$ & 546 & 39.47 \\
2012 & 247 & $25-29$ & 86 & 34.81 \\
\hline
\end{tabular}

Fuente: elaboración propia con datos del INEC (2007-2016).

Es pertinente resaltar que los senegaleses que entraron entre 2007 y 2016 son mayoritariamente hombres ( 98 por ciento). Uno de los rasgos distintivos de la migración senegalesa es que aparte de la masculinidad se relaciona con la juventud; para ellos es la manera de "hacerse hombres», de cumplir con la responsabilidad de mantener a su familia, lo cual explica una migración en una edad temprana (Zubrzycki, 2013).

Al comparar las entradas y las salidas de los migrantes senegaleses entre 2007 y 2016, el periodo 2012 a 2015 tiene otra particularidad. A partir de 2012 se produce un aumento de ingreso al país y se dejan de registrar las salidas más o menos de forma equivalente a las entradas: de 247 ingresos, se notificaron 62 salidas, lo que deja un saldo de 185 (INEC, 2012). En 2015, dicha situación se intensificó con un saldo de 3 mil 402 entradas provenientes de Senegal que se supone siguen dentro del país (INEC, 2015).

Los datos previos revelan que en el lapso observado 6 mil 722 senegaleses se instalaron en Ecuador, puesto que no se registran salidas. De ello se infiere que permanecieron de forma irregular en el país, pasados los tres meses correspondientes a la estadía como turistas, o que salieron por vías clandestinas. Los testimonios recogidos en esta investigación y la aparente ausencia de senegaleses en territorio ecuatoriano permiten argumentar que aquellos que entraron legalmente al país entre 2012 y 2015 salieron de forma irregular hacia el sur con el fin de llegar a Argentina. 


\section{GRÁFICA 2}

Entradas y salidas de migrantes senegaleses entre 2007 y 2016

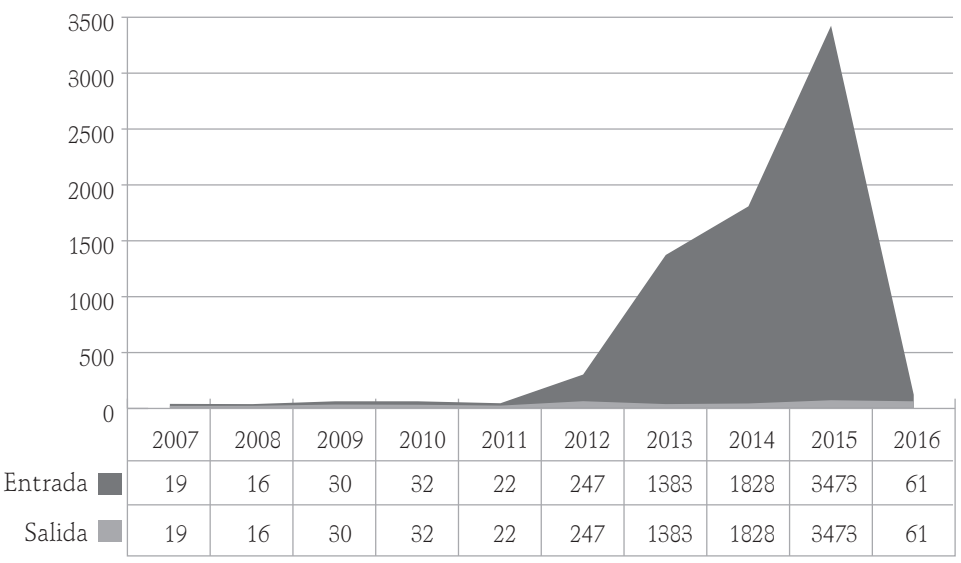

Fuente: elaboración propia con datos del INEC (2007-2016).

Un dato esencial que confirma la condición de Ecuador como nodo articulador entre espacios migratorios es que entre 2013 y 2015 la comunidad senegalesa era la más numerosa dentro de la «migración africana» en el país. En contraposición, durante el trabajo de campo en 2016 y 2017 no se encuentra rastro alguno de ellos en puntos clave como Quito y Guayaquil y en lugares de frontera. La ratificación de este hecho se produjo durante las entrevistas a población africana instalada en la capital, con instituciones públicas y ONG.

Ciertos miembros de la comunidad africana radicada en Quito expresaron tener conocimiento de la presencia en años anteriores de algunos senegaleses que pasaban por la ciudad; sin embargo, parece que no hubo un intercambio notable con ellos, lo que demuestra que la estadía en el país fue corta. Recuerdan verles acudir a los restaurantes, tocar música en la calle o simplemente continuar su viaje hacia Guayaquil. En cualquier caso, si tales presencias efímeras se confirman en el pasado, los mismos interlocutores constatan en la actualidad la no presencia de senegaleses en el territorio ecuatoriano. ${ }^{9}$ De igual manera, los investigadores argentinos consultados ratificaron el hecho de que los migrantes senegaleses transitaban por Ecuador pero en ningún caso se establecían en él. ${ }^{10} \mathrm{Al}$

${ }^{9}$ Entrevista realizada con Steve en Quito el 21 de febrero de 2017; entrevista efectuada con Reve en Quito el 8 de febrero de 2017.

${ }^{10}$ Conversación telefónica con Bernarda Zubrzycki el 16 de febrero de 2017; conversación telefónica con Gisele Kleidermacher el 24 de febrero de 2017. 
respecto, Cheikh, senegalés radicado en Argentina, relata lo siguiente: "Ahora están volviendo (los africanos a Argentina) pero les cuesta por la visa. Tienen que entrar por Brasil u otros por Ecuador (...) por todos lados entran. Pueden morir, estar en la cárcel o cualquier cosa, pero sí pasan (...) muchos entran ilegalmente». ${ }^{11}$

El relato de Malick, otro senegalés radicado en Argentina desde 2014, ${ }^{12}$ también refleja claramente lo efímero del paso por Ecuador y el porqué del desequilibrio entre entradas y salidas. Si bien se registra su entrada regular, la salida se lleva a cabo por diferentes medios; uno de ellos es atravesar la frontera peruana de manera irregular. Malick llegó a Ecuador en 2014 con la dirección de un hotel donde tenía una reserva a su nombre. Unas horas más tarde, unos hombres lo recogieron en el hotel para llevarlo a un autobús que lo trasladó hasta la frontera con Perú. Ahí otras personas le ayudaron a cruzar durante la noche y le proporcionaron información para que pudiera llegar por tierra hasta Bolivia, donde siguió el mismo procedimiento que en la frontera anterior. Posteriormente, pasó de Bolivia a Brasil, donde permaneció ocho meses antes de cruzar a Argentina por vía terrestre. La ruta la dirige un senegalés establecido en Argentina que cuenta con varias personas que trabajan para él en dichos países. Por la información y el apoyo logístico que recibió a lo largo del recorrido migratorio, Malick tuvo que pagar cierta cantidad. ${ }^{13}$

\section{Conformación y desaparición de nodos articuladores entre continentes. El tránsito como facilitador de la configuración de nodos}

A través de las dinámicas migratorias y los datos ya expuestos se demuestra que Ecuador se convirtió en un nodo migratorio en escasos cuatro años para flujos de poblaciones senegalesas, un facilitador de la movilidad dentro de la región sudamericana. Si bien se construye y se desarrolla con fuerza, también se desarticula con la misma velocidad. Muestra de ello son las estadísticas nacionales de entradas

${ }^{11}$ Entrevista telefónica vía Facebook, 17 de abril de 2017.

${ }^{12}$ Entrevista realizada vía WhatsApp el 23 de marzo de 2017.

${ }^{13}$ El entrevistado no quiso revelar el costo por la travesía sudamericana desde Ecuador. Sin embargo, informa que el pago se efectúa en una sola emisión en dólares estadounidenses antes de iniciar el viaje. 
y salidas internacionales de 2016, en las que el número de entradas de visitantes senegaleses descendió a 61 (INEC, 2016). Asimismo, en ese año se equilibró el saldo de entradas y salidas al reportar la misma cantidad (INEC, 2016).

El cambio radical en las cantidades de arribos y el equilibrio de los saldos migratorios coincide con que a principios de 2016 el gobierno ecuatoriano restringió el ingreso sin visa de senegaleses, circunstancia que acabó de forma abrupta con las posibilidades de ingreso fáciles y regularizadas a territorio ecuatoriano. ${ }^{14} \mathrm{Al}$ respecto, destaca uno de los límites de la política de «puertas abiertas» ecuatoriana.15 existe una limitación selectiva en la que se restringe el ingreso de ciertas nacionalidades. La política de apertura de fronteras sufrió modificaciones importantes desde el momento de su implementación. En 2008 se restringió el ingreso sin visa para los ciudadanos chinos, ${ }^{16} \mathrm{y}$ a partir de 2010 para los ciudadanos de Afganistán, Bangladesh, Eritrea, Etiopía, Kenia, Nepal, Pakistán, Nigeria, Senegal y Cuba (OIM, 2013; Ministerio del Interior, 2016). Es decir, la apertura de las fronteras es selectiva según el origen nacional.

La finalidad de la restricción era reducir la entrada de ciudadanos de ciertos países (asiáticos y africanos fundamentalmente) cuya presencia se ha ligado a la existencia de redes de tráfico de migrantes. En el caso senegalés, la política migratoria ecuatoriana influyó en el incremento de dichos migrantes en el territorio; no obstante, a partir de 2016 se modificaron los requisitos de acceso: al exigirles la visa restringieron su llegada (Ministerio del Interior, 2016).

${ }^{14}$ Cabe mencionar que no existe embajada ni consulado ecuatoriano en Senegal, el más cercano se encuentra en Marruecos, de ahí las dificultades para tramitar el visado e ingresar al país.

${ }^{15}$ La política migratoria ecuatoriana tiene una limitación temporal que provoca que, después de un periodo de tres meses, el individuo que ingresó en el país como turista pueda quedarse en situación irregular si no ha tramitado otro tipo de visa. Los migrantes senegaleses que llegaron sin visa a Ecuador antes de 2016 y que optaron por quedarse en el país más de tres meses se enfrentaron a esta problemática. Es importante aclarar que esta regularización implica un gasto económico que normalmente no es accesible a todos. En consecuencia, más que propiciar la llegada e instalación, la medida podría favorecer el tránsito de migrantes hacia países que se conectan con otro tipo de rutas, muchas de ellas inseguras y clandestinas.

${ }^{16}$ Según fuentes periodísticas (El Comercio, 2016), el gobierno chino sospechaba que numerosos ciudadanos aprovechaban la cobertura del turismo para hacer comercio en Ecuador y transitar clandestinamente a Estados Unidos. Lo anterior provocó que el gobierno chino solicitara a Ecuador revertir la medida, efectiva a partir de diciembre de 2008. Otras fuentes de la misma índole pretenden que la reversión fue por motivos de seguridad. Sin embargo, según notifica el Ministerio de Relaciones Exteriores y Movilidad Humana (MREMH) en su página web, en 2016 se celebró un acuerdo entre Ecuador y China para suprimir los visados con propósito de turismo, lo que permitió de nuevo el ingreso de ciudadanos chinos por un periodo de 90 días al año. En el caso chino, se otorga el ingreso por un lapso de 30 días a los turistas ecuatorianos. 
Es probable que las razones por las cuales se estableció esta medida se vinculan con el enfoque securitista desarrollado en el país con más fuerza en los últimos años. En una entrevista con un funcionario público del Ministerio de Relaciones Exteriores realizada en Quito, se abordó el cambio en la perspectiva del gobierno ecuatoriano en los últimos años. ${ }^{17}$ El Ministerio del Interior determinó si el ingreso de ciertas nacionalidades podía constituir un riesgo para el país, y los migrantes que proceden de África suelen identificarse en esos términos. Se considera sospechoso que hagan uso del territorio como punto de tránsito y se les asocia con la realización de actividades ilícitas: tráfico de todo tipo y trata de personas, lo cual ha generado la imposición de medidas restrictivas. En adición, las autoridades ecuatorianas detectaron que algunos de los africanos que llegaban al país hacían uso de la solicitud de refugio para obtener documentos sin que hubiera causa fundada..$^{18}$

Bajo esa lógica, el gobierno ecuatoriano comprobó en las estadísticas de entradas y salidas internacionales el incremento sin precedentes del ingreso de senegaleses, por lo que decidió cerrar los flujos con la imposición de la visa de turismo. En este caso, como en otros tantos, se antepone un discurso de protección de derechos - relacionado con la idea de que un segmento de la población que llegaba podría ser víctima del tráfico de personas - para restringir su arribo al país. Durante la entrevista, la investigadora argentina Bernarda Zubrzycki hacía hincapié en la importancia de analizar el impacto de la solicitud de visas sobre las entradas de migrantes a un país específico. ${ }^{19}$ Así, tras las acciones adoptadas por el gobierno ecuatoriano, las llegadas más intensas de senegaleses a Ecuador se detuvieron radicalmente.

La ausencia actual de senegaleses, en contraste con la situación previa, revela algo fundamental acerca de las formas y dinámicas de movilidad de las poblaciones en tránsito migratorio. Por un lado, frente a un escenario de cierre y securitización generalizado y global, los contextos nacionales suponen ventanas de oportunidad que en una coyuntura concreta propicien el tránsito migratorio mediante la conformación de espacios articuladores entre rutas internacionales.

\footnotetext{
${ }^{17}$ En la entrevista, llevada a cabo el 14 de marzo de 2017, se profundizó sobre el giro del gobierno hacia medidas enfocadas en la seguridad nacional. Incluso, se consideraron inconstitucionales algunas de las prácticas recientes en materia migratoria al no respetar en numerosos casos el debido proceso, al promover deportaciones que tardan entre tres o cuatro meses en tomar una decisión, tiempo en el que las personas permanecen detenidas, procesos de estigmatización con relación a la nacionalidad por parte de las autoridades.

${ }^{18}$ Entrevista realizada en Quito el 14 de marzo de 2017.

${ }^{19}$ Conversación telefónica con Bernarda Zubrzycki el 16 de febrero de 2017.
} 
Por otro lado, en la configuración de esos nodos no sólo intervienen contextos políticos más favorables pues existen otras manifestaciones que hacen posible esa situación; por ejemplo, aquellas dinámicas que tratan de eludir las restricciones a la movilidad, las estrategias desarrolladas por la comunidad migrante que facilitan los canales de desplazamiento y llegada.

\section{Conclusiones}

Los migrantes senegaleses han enfrentado el paradigma de control y seguridad a través de nuevas formas de movilidad, en especial el tránsito migratorio, con la intención de aprovechar contextos más permisivos a escalas nacional y regional. Ello ha resultado en su expansión por países de América del Sur gracias a la conformación de nodos de articulación migratoria (tal es el caso de Ecuador).

El tránsito migratorio como forma de movilidad y estrategia de los senegaleses en su expansión hacia países sudamericanos, en especial hacia Argentina, se fortalece por la apertura de la política migratoria de Ecuador que, a la manera de nodo articulador, se emplaza como territorio que permite llevar a cabo el proyecto migratorio senegalés. La política de «puertas abiertas» implementada desde 2008 comprende una oportunidad para que los planes de acción de algunas poblaciones migrantes puedan cobrar sentido, al ser un espacio prometedor, no explorado y aperturista. Los senegaleses se beneficiaron de esa política hasta finales de 2015, lo que les permitió utilizar Ecuador como lugar de tránsito regularizado. Al poder ingresar libremente, sin necesidad de conseguir con anterioridad una visa de viaje, los migrantes senegaleses se desplazaron sin complicaciones durante varios años y lograron adentrarse a la región sudamericana sin tener que justificar los motivos por los que llegaron a Ecuador.

No obstante, la imposición de visas obstaculizó las oportunidades que ofrecía el país como espacio conector o canalizador de la migración senegalesa hacia América del Sur. La medida refleja con claridad las falencias de la política de «fronteras abiertas» y del principio de ciudadanía universal promulgado por la Constitución de 2008, pues promueve la migración irregular y provoca una jerarquización en el acceso a los derechos fundamentales. ${ }^{20}$ El cambio en la política

${ }^{20}$ Aunque se supone que al ingresar a Ecuador todos los individuos gozan de los mismos derechos y obligaciones, en realidad su acceso y disfrute tiene que ver con el origen nacional y la clase social, puesto que se establece una suerte de escala: desde aquellos que no pueden obtener una visa, hasta 
migratoria obligó a los senegaleses a modificar la estrategia que los conducía a Argentina por una en la que ahora se dirigen a Brasil, país que desde antes funcionaba como lugar de instalación y tránsito. Por tanto, las políticas ecuatorianas han tenido un impacto directo en la migración senegalesa, al punto de reconfigurar formas y dinámicas de movilidad en la región, y de articular la conexión entre distintos continentes.

\section{Referencias}

Aderanti, Adepoju (2004), "Trends in international migration in and from Africa», en Douglas, Massey y Taylor Edward (eds.), International migration: prospects and policies in a global market, pp. 59-76, New York, Oxford University Press, en http://www. cespi.it/CESPI-SID/Adepojou-international_migration_Africa.pdf

Álvarez Velasco, Soledad (2015), "Confronting violence and border control along the Ecuador-Mexico-US zone of transit», en Ruben Andersson (ed.), Themed blog series on the industry of illegality, Oxford, Universidad de Oxford, en https://www.law. ox.ac.uk/research-subject-groups/centre-criminology/centreborder-criminologies/ blog/2015/10/confronting

(2012), «Imágenes de violencia contemporánea: aproximaciones a la realidad del corredor migratorio México-Estados Unidos», en Yerko Castro Neira (ed.), La migración y sus efectos en la cultura, pp. 181-210, México, Consejo Nacional para la Cultura y las Artes.

Bakewell, Olivier (2009), «South-South migration and human development: reflections on African experiences», Human Development Research Paper 2009-07, United Nations Development Programme, en http://hdr.undp.org/sites/default/files/hdrp_2009 07. pdf

Corbetta, Piergiorgio (2007), Metodología y técnicas de investigación social, McGraw-Hill Interamericana.

Düvell, Franck, Irina Molodikova y Michael Collyer (2014), Transit Migration in Europe, IMISCOE Research/Amsterdam University Press, en http://nl.aup.nl/download/ Look\%20Inside\%20Transit\%20Migration.pdf

quienes pueden ingresar 90 días sin restricción, pero son incapaces de costear el cambio de visa o inscribirse dentro de las categorías migratorias propuestas por el Estado, como es el caso de inversionistas, amparados por un ciudadano ecuatoriano o migrantes calificados, lo que les obliga a permanecer en situación irregular. 
(2012), «Transit migration: a blurred and politicised concept», Population, Space and Place (18), pp. 415-427.

Galeano Marín, María Eumelia (2004), Diseño de proyectos en la investigación cualitativa, Medellín, Fondo Editorial Eafit.

Icduygu, Ahmet y Deniz Yukseker (2012), «Rethinking transit migration in turkey: reality and representation in the creation of a migratory phenomenon", Population, Space and Place (18), pp. 441-456.

Instituto Nacional de Estadísticas y Censos (INEC) (2007, 2008, 2009, 2010, 2011), «Anuario de entradas y salidas internacionales», Ecuador, en http://www.ecuadorencifras.gob.ec/migracion-bases-de-datos/

(2012), "Anuario de entradas y salidas internacionales», Ecuador, en http:// www.ecuadorencifras.gob.ec/migracion-2012/

(2013), «Anuario de entradas y salidas internacionales», Ecuador, en http:// www.ecuadorencifras.gob.ec//migracion-2013/

(2014), «Anuario de entradas y salidas internacionales», Ecuador, en http:// www.ecuadorencifras.gob.ec/documentos/web-inec/Poblacion_y_Demografia/ Migracion/Publicaciones/Anuario_ESI_2014.pdf

(2015), «Anuario de entradas y salidas internacionales», Ecuador, en http:// www.ecuadorencifras.gob.ec/entradas-y-salidas-internacionales-2015/

(2016), «Anuario de entradas y salidas internacionales», Ecuador, en http:// www.ecuadorencifras.gob.ec/migracion/

Kabunda, Mbuyi (2007), "Las migraciones africanas más horizontales que verticales», Pueblos (28), en http://www.revistapueblos.org/old/spip.php?article671

Kleidermacher, Gisele (2012), «Migración Sur-Sur: senegaleses en la ciudad de Buenos Aires», Voces en el Fenix (21), pp. 108-115, en http://www.vocesenelfenix.com/ content/migraci\%C3\%B3n-sur-sur-senegaleses-en-la-ciudad-de-buenos-aires

Maffia, Martha (2010), «Una contribución al estudio de la nueva inmigración africana subsahariana en la Argentina», Cuadernos de antropología social (31), en http://www. scielo.org.ar/scielo.php?script=sci_arttext\&pid=\$1850-275X2010000100001

Ministerio del Interior (2016), Requisitos para ingresar a Ecuador, Ecuador, en http:// www.ministeriointerior.gob.ec/requisitos-para-ingresar-a-ecuador/

Morales, Orlando Gabriel (2011), «Nueva corriente de migrantes africanos en Argentina y reconfiguraciones de la invisibilidad de la negritud en el contexto actual», en Guzmán, Florencia y Geler, Lea, Actas de las Segundas Jornadas de Estudios Afrolatinoamericanos del GEALA, pp. 157-172, Buenos Aires, Instituto Ravignani-UBA, en http://www.academia.edu/5288735/Nueva_corriente_de_migrantes_africanos_ 
en_Argentina_y_reconfiguraciones_de_la_invisibilidad_de_la_negritud_en_el_ contexto_actual

Murillo, Juan Carlos (2010), «Migración extracontinental en América Latina: algunas tendencias y consideraciones de protección international», Alto Comisionado de las Naciones Unidas para los Refugiados OAS Workshop, en http://www.acnur.org/t3/ fileadmin/scripts/doc.php?file=t3/fileadmin/Documentos/BDL/2010/7720

OIM (Organización Internacional para las Migraciones) (2013), "Migrantes extracontinentales en América del Sur: estudio de casos», Cuadernos Migratorios (5), en https:// publications.iom.int/system/files/pdf/cuaderno5_migrantes_extracontinentales _americadelsur.pdf

Papadopoulou, Aspacia (2005), «Exploring the asylum migration nexus: a case study of transit migrants in Europe», Global Migration Perspectives (23), en http://www. iom.int/jahia/webdav/site/myjahiasite/shared/shared/mainsite/policy_and research/gcim/gmp/gmp23.pdf

Wabgou, Maguemati (2008), "América Latina: ¿̇Nuevo destino de los inmigrantes africanos o nueva etapa en su periplo hacia EEUU?»,, Observatorio sobre la Realidad Social del África Subsahariana (FCA-UAM), en http://docplayer.es/13208776-America-latinanuevo-destino-de-los-inmigrantes-africanos- o-nueva-etapa-en-su-periplo-haciaeeuu.html

Zubrzycki, Bernarda (2013), «Nuevos destinos de la migración africana reciente: los senegaleses en Argentina», Travessia (72), pp. 31-40, en http://www.academia. edu/11883017/Nuevos_destinos_de_la_migraci\%C3\%B3n_africana_reciente los_senegaleses_en_Argentina 